\title{
College English Teaching Innovation and Challenge in MOOC Environment
}

\author{
Rong Li \\ Sichuan vocational and technical college, Suining, Sichuan province, 629000, China.
}

\begin{abstract}
Keywords: MOOC, online courses, multimedia teaching, college English teaching, innovation and
\end{abstract} challenge.

\begin{abstract}
With the development of modern information technology, the large-scale open online courses (MOOC) as a new online course development model has become the focus of attention of the global colleges and universities in recent years. In the era of MOOC, global free sharing of high-quality curriculum resources allows all learners to freely adjust the content of the learning courses. All students in the school can independently choose relevant courses to study. Compared with the traditional teaching model, although the characteristics of MOOC are distinct, MOOC also constructs a complete teaching link, including class explanation, interaction, feedback, Q\&A, homework analysis, course arrangement, posting, and forum. Many features such as "new", "large-scale”, “open”, “online” and so on determine its teaching mode has more advantages such as convenience, flexibility and low cost. Because of these inherent advantages, MOOCs have been developing rapidly in the world in recent years and have had a profound impact on the field of higher education at home and abroad.
\end{abstract}

\section{Introduction}

MOOCs originate from the traditional curriculum development model. They mainly support the participation of large-scale groups of people through the means of lecturers, through the teaching of lectures, practice exercises, discussion modes, and interactive methods. The MOOC was proposed by Dave Cormier, University of Prince Edward Island, Canada, and Bryan Alexander, a senior research fellow at the National Institute of Humanities Educational Technology Application. In 2012, universities such as Stanford University, the University of California, and the University of Michigan at Princeton University all launched large-scale open courses on the Internet. Therefore, they are called the "MOOC first year." The development of MOOC between China and the world is almost in sync. Furan University and Shanghai Jiao tong University were the pioneers. Then Peking University and Tsinghua University also began to join this MOOC camp in 2013. Therefore, 2013 was called "China MOOC First Year". . The frequent interaction between China's prestigious schools and MOOC companies in the short term proves that MOOC, a brand-new education model, has brought tremendous impact on Chinese high education.

MOOC is an important part of the reform of modern teaching model in colleges and universities. It uses the Internet as a platform and uses various information technologies and social networks to organically combine curriculum design, virtualized teaching content, teaching exchange, application innovation, and evaluation feedback. A complete course teaching process for learning, discussing and communicating, completing assignments, taking exams, obtaining scores, etc. was constructed for a learner online course video. From this we can see that the MOOC teaching model has its own teaching characteristics relative to traditional classroom teaching.

PBL is a brand-new teaching model that takes questions as the core, solves questions as the driving force, and uses groups to explain, display, discuss, and communicate with each other as a means to inspire students to take the initiative in self-study and cultivate students' innovative thinking. This teaching model takes the learner as the center, sets the problem as the starting point of learning, and puts the learning into meaningful and complex problem situations by designing real tasks, and allows the students to construct themselves through independent inquiry, study group, and teacher guidance. Knowledge, in the process of solving problems, grasps the knowledge behind the problems and forms 
the ability to learn independently. The PBL teaching model has the following basic elements: First, it is student-centered; students must take up the responsibility for learning; secondly, problems are the starting point; all the learning content of the students is structured on the basis of the problem; Cooperative learning and self-directed learning are the main forms; learners can develop their abilities and collaborative skills through social interaction; fourth, problems must be unstructured issues that students may encounter in the "real world" of their future; there is no fixed solution.

\section{The Proposed Methodology}

\subsection{College English MOOC Teaching Model Design.}

According to the College English MOOC teaching process design, each week, the teacher can teach 1 class hour, and conduct 1 class hour class discussion on the course unit content. The rest of the time is for the students to watch the video teaching themselves. The entire teaching process includes self-learning and knowledge acquisition before class, internalized knowledge of teachers in class, and self-learning to consolidate and expand knowledge after class. Students can actively participate and improve teaching through pre-class preparation, class discussion, and after-school digestion. The purpose of the effect and the Internet provides students with various learning resources. Mobile learning terminals such as smartphones and iPads provide learning tools for individualized self-study, making it possible to fragment and personalize mobile learning.

Students independently select online learning locations and independently select learning content to watch MOOC videos according to their own learning conditions. Teachers design a small test in the video as a level to enter the next stage of learning, so that learning is like playing games, which can effectively improve students. The focus if the students do not understand the words, they will not be able to pass the checkpoints. Smart will learn to learn again. Through repeated practice, students will become more knowledgeable.

MOOC reformed the traditional indoctrination teaching model. Students are no longer passively accepting knowledge. The core of MOOC is student learning. Students have strong discourse power and initiative, teachers play a leading role, and students are the main body of learning. MOOC Classroom teaching mainly uses task-based teaching methods.

Teachers can supplement the cultural background knowledge, aim at the teaching objectives of the lesson, the key teaching difficulties, and the problems that arise in the student's self-study before class, improve the students' cross-cultural knowledge, and design problems related to the topic of the text to create problem situations. The teaching objectives propose time-limited, inquiring tasks.

Students are encouraged to conduct inquiry-based group learning, discuss and discuss in groups, discuss and solve problems, complete tasks, and form a hybrid online and offline teaching model. This kind of collaborative inquiry activities in the form of deliberations, debates, and other forms embodies the dominant position of student learning and is conducive to cultivating students' communication skills and students' abilities of autonomy, cooperation, and inquiry learning. By grouping design exploration programs, students' innovative thinking and critical thinking are explored, and students' basic thinking and methods for logical thinking and scientific inquiry are cultivated.

\subsection{The Influence of MOOC on College English Teaching Model.}

As we all know, Chinese college English teaching has long been dominated by classroom-centered, teacher-centered, and textbook-centered "three-center" teaching models. Due to the shortage of educational resources in colleges and universities in China, college English teaching still adopts a collective class model. Each class is basically more than 60 people. In this situation, the college English education in China is not only difficult to improve students' ability to use English, but also difficult to achieve personalized development. The widespread use of MOOCs will have a profound effect on learners' learning. On the one hand, through the MOOC online course, students can use the social network to participate in learning and discussion while sharing the native language teaching of foreign teachers, form a good interaction in the discussion area, and build a good learning atmosphere 
for the students; on the other hand, According to the Internet's MOOC platform, students are free to choose the time and space for learning English, select interesting English course content for targeted learning, and also be able to repeatedly learn online micro-curriculum video content and be more fully prepared for testing. These are conducive to the improvement of students' individualized English learning ability.

At present, the classroom teaching of English teachers in most colleges and universities in China still focuses on teaching materials. Course design still focuses on PPT courseware production and demonstration. Therefore, college English teachers only play the role of "executor" rather than "designer" and "director" in the teaching process. As college English teachers in the era of MOOC, their required teaching skills and curriculum design skills should be improved. First of all, college English teachers should be more familiar with computer software related knowledge and operations to produce teaching videos, design teaching courseware, etc., pay more attention to the online organization of student learning and receive student feedback, and maintain communication with students to solve students in English learning proposed question. Second, under the MOOC environment, college English teachers should continuously improve the design ability of college English courses to provide higher quality, more targeted teaching resources to share discussion and research learning with students. Finally, for teachers involved in MOOC teaching, only mastering the professional knowledge and skills is not enough to adapt to the change of this new teaching model. Instead, they should master richer multi-disciplinary knowledge to improve their own qualities in order to guide online more effectively. Students complete their learning tasks and better participate in the competition for college English education in the era of MOOC.

MOOC emphasizes the complementary advantages of online e-learning and classroom teaching. The integration of the two is a mode of teaching that is more in line with the needs of learners at different levels. College English teaching should take advantage of MOOC's new teaching model and conduct mixed-mode classroom teaching from face-to-face courses, video courses and discussion courses.

The interactive and transparent MOOC learning environment requires college English teachers to change their teaching concepts and become mentors and cooperators of student learning. Therefore, teachers must not only strengthen professional learning and raise their awareness of competition, but also improve teachers' design and use of MOOC's information technology literacy. Yankee Institute of Technology English teachers make full use of digital portable devices (PDAs) for ubiquitous learning (u-Learning), constantly updating their knowledge structure, and sharing learning experiences with English teachers in universities within the Union through the establishment of QQ groups.

\subsection{PBL Teaching Mode in MOOC Environment.}

Resources and environment. With the popularization of mobile communication devices such as iPad, laptops, and smart phones, the combination of mobile networks and the Internet, almost everyone can access the Internet at any time. Coupled with the high-speed transmission rates of 3G, $4 \mathrm{G}$, and fiber, teachers can put text, sound, images, and even video resources on the Internet through E-mail and QQ groups for students to download, browse, and learn. Students can easily "face to face each other" at any time between teachers and students. In addition, free Wi-Fi is available in places other than classrooms and libraries, such as buses, subways, and airport lounges. Students can access learning materials anytime and anywhere and can use any leisure time to study.

Information technology. Since 2012, MOOC has swept the globe as many famous universities such as Harvard University, MIT, Peking University, Tsinghua University, and Hong Kong University have opened their own large-scale open courses. The Coursers, Audacity, and eddy are the three-segment car internet teaching platforms that have already recruited lectures from outstanding teachers from famous universities. Due to the openness and diversity of MOOC's curriculum resources, the need for open and accessible curriculum resources can be exchanged and shared. Students around the world have the opportunity to enter top universities and reach out to top 
academics. The MOOC platform is one of the world's top elite teachers and masters, which will surely benefit learners.

The final stage of the PBL teaching model is learning assessment. Thanks to the MOOC platform, learning assessments have also become more diverse. First of all, the mastery of knowledge can be borrowed from the in-line tests in MOOC teaching videos. Test items that jump out at regular intervals can be an aspect of the assessment content. Secondly, student performance evaluation mainly consists of two aspects. In the group exchange and sharing, team members evaluate each other's self-study situation and the intermediate performance of the exchange; each discussion in the class ends, and on the basis of student's mutual appraisal, the teacher bases on students' Self-evaluation, self-discussed performance, team learning and cooperation, etc.

\subsection{The Necessity of MOOC in English Teaching.}

University teachers and students in different disciplines are using MOOC. MOOC is still at an exploratory stage in the reform of college English education and teaching. Needless to say, MOOC can not only improve the shortcomings of the traditional teaching model, but also play an extremely important role in perfecting existing teaching systems, inspiring students' interest in learning, expanding students' English thinking, and cultivating students' subjective initiative. Therefore, the deepening of reform in college English teaching cannot be separated from the support of MOOC.

The rise of MOOCs has made great changes in the role of English teachers in the teaching process. The traditional teaching model is that the teacher is the main thread throughout the entire teaching process, while the English teaching in the MOOC model is student-centered, giving full play to the students' subjective initiative throughout the teaching process. Under the MOOC teaching model, English teachers need to rely more on modern education technology and the Internet to elaborate and publish micro-videos and other rich learning resources in order to complete the knowledge system and construct the curriculum elements. At the same time, more class time is needed. Students are actively encouraged to solve problems, deepen their understanding, and expand their thinking through active participation in discussions, exchanges, thought collisions, and sharing. To adapt to this new teaching model as quickly as possible, college English teachers need to change their concepts, change their working methods, and reshape the role of teachers.

\section{Conclusion}

MOOC extends the traditional teacher-student relationship beyond the classroom. In the spare time, students can ask teachers and students online to discuss problems encountered during homework and pre-learning, and exchange learning experiences; teachers can also receive jobs through the network. , push job corrections, and share assignments to explain video, so that students can fully grasp the knowledge they have learned. Obviously, after MOOC introduces the whole teaching session, teachers can effectively supervise and help students to complete after-school homework and pre-learning, break through this blind spot in traditional teaching, and change from a traditional after-school assignment review examiner to a spare time.

\section{References}

[1]. Liu, K., 2017. 127. An Empirical Study on College English O2O Teaching System Based on MOOC Education. Revisit de la Faulted de Ingeniería, 32(14).

[2]. Dejuan, W, Dejuan, W. and Dejuan, W., 2017. The teaching resource development analysis of Micro Learning Resource and MOOC in information teaching. Revisit de la Faulted de Ingeniería, 32(3), pp.271-278.

[3]. Li, S., 2017. 53. Design and Interaction Analysis of Modern College English Classroom Teaching Based on MOOC Mode and Internet Platform. Bulletin Ticino, ISSN: 0376-723X, 55(19). 
[4]. Chengxia, C., 2017. College English Writing MOOC Design \& Practice Based on the Online Writing Platform. Science Journal of Education, 5(4), p.150. 